\title{
Deep sea water improves exercise and inhibits oxidative stress in a physical fatigue mouse model
}

\author{
HUIJIE FAN ${ }^{1,2^{*}}$, ZHANGBIN TAN $^{1 *}$, YUE HUA $^{1 *}$, XIAOFANG HUANG $^{1}$, \\ YITING GAO $^{1}$, YUTING WU ${ }^{1}$, BIN LIU ${ }^{1,3}$ and YINGCHUN ZHOU ${ }^{1,2}$ \\ ${ }^{1}$ School of Traditional Chinese Medicine, Southern Medical University; ${ }^{2}$ Department of Traditional \\ Chinese Medicine, Nanfang Hospital, Southern Medical University, Guangzhou, Guangdong 510515; \\ ${ }^{3}$ Department of Cardiology, The Second Affiliated Hospital of Guangzhou Medical University, \\ Guangzhou Medical University, Guangzhou, Guangdong 510260, P.R. China
}

Received December 31, 2015; Accepted March 17, 2016

DOI: $10.3892 / \mathrm{br} .2016 .651$

\begin{abstract}
Physical fatigue is extremely common and occurs daily, and is considered to be associated with oxidative stress. The diverse functions of deep sea water (DSW) have recently gained increasing attention. Previous studies have emphasized the anti-fatigue effect of DSW, but the intrinsic mechanism behind the effect remains to be elucidated. In the imprinting control region (ICR) mice model, DSW delayed the exhaustive swimming time. In addition, DSW decreased the area under the blood lactate (BLA) curve, which was associated with the area under the BLA curve of pre-swimming, post-swimming and post-rest. Furthermore, DSW reduced the basal levels of malondialdehyde and the post-swimming concentration of blood urea nitrogen, lactate dehydrogenase and creatine kinase after swimming, along with an increase in the normal level of antioxidant enzyme activity such as superoxide dismutase and glutathione peroxidase. However, no significant effect on body weight, hepatic glycogen and muscle glycogen was observed between any group. In conclusion, DSW can improve the athletic ability and alleviate physical fatigue of ICR mice. This effect is achieved by enhancing the antioxidant capacity.
\end{abstract}

Correspondence to: Professor Yingchun Zhou, School of Traditional Chinese Medicine, Southern Medical University, 1838 North Guangzhou Avenue, Guangzhou, Guangdong 510515, P.R. China E-mail: zhychun@126.com

Dr Bin Liu, Department of Cardiology, The Second Affiliated Hospital of Guangzhou Medical University, Guangzhou Medical University, No. 250 Changgang Dong Road, Guangzhou, Guangdong 510260, P.R. China

E-mail: xmhool@163.com

*Contributed equally

Key words: deep sea water, physical fatigue, antioxidants, trace elements

\section{Introduction}

Fatigue is a term used for physical exhaustion, which is highly prevalent within the stressed modern human societies. Fatigue is a symptom of the body not being able to sustain a given level of activity. Fatigue has a negative effect on various aspects of human life including physical strength, work performance, domesticity and social life $(1,2)$.

Increasing evidence has proved that fatigue is closely associated with oxidative stress $(3,4)$. In 1982 , the study by Davies et al (5) confirmed that radicals increase significantly following exhaustive exercise, which supports the theory that exercise may induce an increased production of radicals. An increased generation of radicals during exercise and decreased exercise capacity are most closely associated with the performance of radicals and the lipid peroxidation in the biofilm of various organs. Oxidative stress can be attributed to exercise whereas the reactive oxygen species (ROS) are the foremost cause of exercise-induced disturbances. By contrast, beneficial effects of antioxidants occur during anti-fatigue $(6,7)$. As a result, a number of studies investigating functional foods focus on ROS generation and their performance on antioxidant activity and to demonstrate the role of fatigue resistance.

Deep sea water (DSW) is extracted from >200 meters below the sea level. DSW has received increasing attention for various beneficial characteristics, such as low temperature, nutrition, sterility, stability and safety (8-10). It is known that high atmospheric pressure contributes to small and stable water molecules, ionization state and easy absorption of DSW.

More than 90 types of mineral, such as magnesium $(\mathrm{Mg})$, calcium, sodium and potassium, as well as microelements, such as cobalt, selenium, chromium and vanadium, have been found in DSW (11). Numerous studies have confirmed that DSW has pharmacological effects, including protecting the cardiovascular system $(12,13)$, improving metabolic processes $(14,15)$, anti-osteoporosis properties (16), treating atopic dermatitis skin lesions (17), accelerating recovery from physical fatigue (18), providing intestinal protection against duodenal ulcers (9) and inhibiting the metastatic potential of human breast cancer cell lines (19). 
Although DSW has already been studied for its alleviating fatigue effect in Wistar rats, the beneficial effects isolated in that study were only attributed to the minerals of DSW (20). In addition, the mechanism behind the beneficial effect has not yet been fully clarified. As aforementioned, fatigue is associated with oxidative stress. The present study aimed to determine whether DSW achieved this effect by antioxidant properties. To test this hypothesis, the antioxidant and antifatigue effects of DSW in imprinting control region (ICR) mice were assessed.

\section{Materials and methods}

Materials. DSW was provided by Pacific Deep Ocean Biotech Co., Ltd. (Hualian, Taiwan), which was collected from the West Pacific Ocean (662 meters in depth). Microbes and macromolecules were filtered out through reverse osmosis. Table I shows the composition of DSW subsequent to being concentrated, and the content was assessed by SGS Institut Fresenius GmbH (Dresden, Germany). Glycogen, blood lactate (BLA), superoxide dismutase (SOD), glutathione peroxidase (GSH-Px) and malondialdehyde (MDA) kits were purchased from Nanjing Jiancheng Bioengineering Institute (Nanjing, China). Blood urea nitrogen (BUN), lactate dehydrogenase (LDH) and creatine kinase (CK) levels were measured by the Clinical Laboratory of Traditional Chinese Medicine Integrated Hospital of Southern Medical University (Guangzhou, China).

Animals. The male ICR mice, each weighing $32 \pm 2 \mathrm{~g}$ (specific pathogen-free), were purchased from Hunan SJA Laboratory Animal Co., Ltd. (Hunan, China). The mice were housed within a temperature of $22-26^{\circ} \mathrm{C}$, humidity of $40-60 \%$, and a light/dark cycle of $12 \mathrm{~h}$, respectively. All the procedures involving laboratory animal use were performed in accordance with the guidelines of the Institute of Animal Care and Use Committee of Southern Medical University.

Methods. Prior to conducting the experiment, mice were allowed to adapt to the new environment for 1 week. A total of 192 mice were divided into the following 4 groups: i) Control; ii) DSW-high dose; iii) DSW-middle dose; and iv) DSW-low dose groups. Mice in group I were forced to participate in a weight-loaded swimming test $(n=48)$. BLA was measured in the mice in group II $(n=48)$. BUN, LDH and CK levels were measured in the mice in group III $(n=48)$. Hepatic glycogen and muscle glycogen levels were measured in the mice in group IV $(\mathrm{n}=48)$. In each group, mice were further evenly subdivided into 4 subgroups ( $\mathrm{n}=12)$ : i) Control group, distilled water; ii) DSW-high dose group, $2.3 \mathrm{mg} / \mathrm{ml} \mathrm{Mg}^{2+}$; iii) DSW-middle dose group, $0.92 \mathrm{mg} / \mathrm{ml} \mathrm{Mg}^{2+}$; and iv) DSW-low dose group, $0.46 \mathrm{mg} / \mathrm{ml} \mathrm{Mg}^{2+}$.

Every morning, the mice received a $0.8-\mathrm{ml}$ dose of distilled water or DSW by intragastric administration. After a period of 30 min following the intragastric administration, all the mice were trained to swim for 15 min once and three times a week. This experiment lasted for 4 weeks. The night before forced swimming or blood collection, all the mice were fasted overnight. All experiments were conducted according to the National Institutes of Health Guide for Care and Use of Laboratory Animals.
Table I. Mineral content of deep sea water used in the study.

\begin{tabular}{lc}
\hline Parameter & Content, mg/l \\
\hline Magnesium & 45,300 \\
Calcium & 51.5 \\
Sodium & 11.6 \\
Kalium & 14,800 \\
Ammonium & 13,400 \\
Chloride & 13,200 \\
Bromide & 2,400 \\
Iodine & 4.4 \\
Nitrite & 0.38 \\
Nitrate & 100 \\
Sulfate & 45,700 \\
Manganese & $<0.05$ \\
Iron & 0.05 \\
Chromium & 0.07 \\
Cobalt & 0.007 \\
Copper & 0.044 \\
Nickel & 0.16 \\
Selenium & 0.002 \\
Rubidium & 4.7 \\
Zinc & $<0.05$ \\
Chromium & 0.07 \\
Boron & 135 \\
\hline
\end{tabular}

Mineral content was analyzed by SGS Institut Fresenius $\mathrm{GmbH}$ (Dresden, Germany).

The experimental plan is exhibited as a flow diagram in Fig. 1.

Weight-loaded forced swimming test (group I). After a period of $30 \mathrm{~min}$ following the last intragastric administration, the mice were individually placed in a swimming pool $(45 \times 45 \times 55 \mathrm{~cm})$ that was $40 \mathrm{~cm}$ in depth, and had a temperature of $25 \pm 1^{\circ} \mathrm{C}$. A tin wire ( $2 \%$ of the body weight) was attached to the tail root of the mouse. The pool was too deep for the mice to make contact with the bottom of the pool. The time from the mice being placed into the pool to when they failed to rise to the surface of the water for $10 \mathrm{sec}$ was recorded.

Determination of BLA (group II). After a period of $30 \mathrm{~min}$ following the last intragastric administration, $20 \mu \mathrm{l}$ of venous blood was collected from the posterior orbit of each mouse. The mice were subsequently placed into the pool (at $25 \pm 1^{\circ} \mathrm{C}$ ) to swim for $10 \mathrm{~min}$ in the case of non-weighted-loading. Following swimming, two samples of venous blood were immediately collected from the posterior orbit. A third sample of blood was collected after a period of rest for $20 \mathrm{~min}$. The area under the BLA curve was calculated as 5x (BLA content prior to swimming $+3 x$ following swimming $+2 x$ resting for $20 \mathrm{~min}$ ). The formula was as described previously, in the Chinese Technical Standards for Testing and Assessment of Health Food (2003) (21). 
Table II. Effects of DSW on the body weight of imprinting control region mice.

\begin{tabular}{|c|c|c|c|c|c|c|c|c|}
\hline \multirow[b]{3}{*}{ Group } & \multicolumn{8}{|c|}{ Body weight, g } \\
\hline & \multicolumn{2}{|c|}{ Group I } & \multicolumn{2}{|c|}{ Group II } & \multicolumn{2}{|c|}{ Group III } & \multicolumn{2}{|c|}{ Group IV } \\
\hline & Initial & Final & Initial & Final & Initial & Final & Initial & Final \\
\hline Control & $32.1 \pm 0.8$ & $35.0 \pm 1.5$ & $31.6 \pm 0.9$ & $37.2 \pm 2.0$ & $31.3 \pm 1.1$ & $36.1 \pm 1.0$ & $31.9 \pm 0.8$ & $36.5 \pm 1.6$ \\
\hline DSW-H & $32.3 \pm 0.7$ & $36.7 \pm 2.4$ & $31.1 \pm 1.1$ & $36.5 \pm 1.2$ & $31.0 \pm 1.5$ & $35.1 \pm 2.2$ & $32.0 \pm 0.8$ & $37.0 \pm 2.4$ \\
\hline DSW-M & $32.1 \pm 1.1$ & $35.5 \pm 1.9$ & $31.9 \pm 1.2$ & $36.5 \pm 1.6$ & $31.4 \pm 0.8$ & $34.8 \pm 0.8$ & $31.9 \pm 1.2$ & $37.2 \pm 1.5$ \\
\hline DSW-L & $31.1 \pm 0.9$ & $35.2 \pm 1.8$ & $31.7 \pm 1.1$ & $36.1 \pm 1.7$ & $31.1 \pm 1.1$ & $35.3 \pm 1.8$ & $31.9 \pm 1.0$ & $35.2 \pm 1.6$ \\
\hline
\end{tabular}

Data are mean \pm standard error of the mean. DSW, deep sea water; $\mathrm{H}$, high-dose group $\left(2.3 \mathrm{mg} / \mathrm{ml} \mathrm{Mg}^{2+}\right)$; M, middle-dose group (0.92 mg/ml $\left.\mathrm{Mg}^{2+}\right)$; L, low-dose group $\left(0.46 \mathrm{mg} / \mathrm{ml} \mathrm{Mg}^{2+}\right)$; group I, mice underwent weight-loaded forced swimming test; group II, blood lactose level was determined following non-weight-loaded swimming; group III, blood urea nitrogen, lactate dehydrogenase and creatine kinase levels were determined following non-weight-loaded swimming; group IV, glycogen, superoxide dismutase, glutathione peroxidase and malondialdehyde were measured following non-weight-loaded swimming.

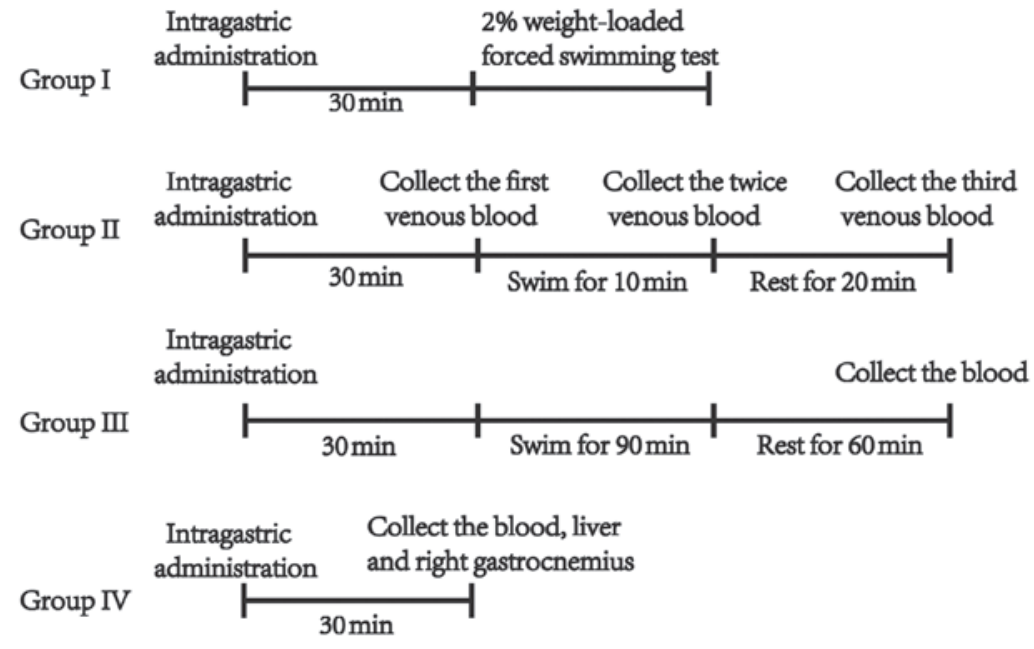

Figure 1. Flow diagram of the experimental plan.

Table III. Effects of DSW on the weight-loaded forced swimming test of imprinting control region mice.

\begin{tabular}{lc}
\hline Group & Swimming time, sec \\
\hline Control & $2,517.8 \pm 574$ \\
DSW-H & $3,240.3 \pm 875^{\mathrm{a}}$ \\
DSW-M & $2,503.7 \pm 612$ \\
DSW-L & $2,523.0 \pm 513$ \\
\hline
\end{tabular}

${ }^{\text {a }} \mathrm{P}<0.05$ compared to the control group. Data are mean \pm standard error of the mean. DSW, deep sea water; $\mathrm{H}$, high-dose group $(2.3 \mathrm{mg} / \mathrm{ml}$ $\left.\mathrm{Mg}^{2+}\right)$; $\mathrm{M}$, middle-dose group $\left(0.92 \mathrm{mg} / \mathrm{ml} \mathrm{Mg}^{2+}\right)$; L, low-dose group $\left(0.46 \mathrm{mg} / \mathrm{ml} \mathrm{Mg}^{2+}\right)$.

Determination of BUN, LDH and CK (group III). After a period of $30 \mathrm{~min}$ following the last intragastric administration, mice were individually forced to swim for $90 \mathrm{~min}$ with non-weight-loading. The mice subsequently rested for $60 \mathrm{~min}$. Following rest, whole blood samples were collected by extirpating the left eyeball in tubes without anticoagulant and the mice were sacrificed. The blood sample was placed at $4^{\circ} \mathrm{C}$ for $3 \mathrm{~h}$, and centrifuged at $1,800 \mathrm{x}$ g for $15 \mathrm{~min}$. BUN, LDH and CK levels of each serum sample were tested by the Roche Cobas Integra 6000 modular biological immune analyzer (Roche Diagnostics, Basel, Switzerland) in the Clinical Laboratory of Traditional Chinese Medicine Integrated Hospital of Southern Medical University.

Determination of glycogen, SOD, GSH-PX and MDA (group IV). After a period of $30 \mathrm{~min}$ following the last intragastric administration, the whole blood samples were collected by extirpating the left eyeball in tubes without anticoagulant. The liver and right gastrocnemius muscle were collected immediately, and dried with absorbent paper following washing with physiological saline. The samples were maintained at $-80^{\circ} \mathrm{C}$ until analysis of glycogen content. Simultaneously, the blood sample was placed at $4^{\circ} \mathrm{C}$ for $3 \mathrm{~h}$, and centrifuged at $1,800 \mathrm{x}$ g for $15 \mathrm{~min}$. In addition, the plasma SOD and GSH-Px activities and MDA levels was measured in the serum. All these methods followed the manufacturer's 
Table IV. Effects of DSW on BLA in imprinting control region mice.

$\mathrm{BLA}, \mathrm{mmol} / \mathrm{l}$

\begin{tabular}{lcccc}
\cline { 2 - 4 } Group & Pre-exercise & Post-exercise & Post-rest & Area under BLA curve \\
\hline Control & $6.6 \pm 1.3$ & $11.4 \pm 1.6$ & $9.5 \pm 1.0$ & $298.6 \pm 34.0$ \\
DSW-H & $5.5 \pm 1.3^{\mathrm{a}}$ & $8.9 \pm 1.1^{\mathrm{b}}$ & $6.4 \pm 1.2^{\mathrm{b}}$ & $228.2 \pm 23.2^{\mathrm{b}}$ \\
DSW-M & $5.5 \pm 1.2^{\mathrm{a}}$ & $8.7 \pm 1.6^{\mathrm{b}}$ & $6.9 \pm 1.2^{\mathrm{b}}$ & $227.2 \pm 37.0^{\mathrm{b}}$ \\
DSW-L & $4.4 \pm 1.1^{\mathrm{b}}$ & $9.7 \pm 1.5^{\mathrm{b}}$ & $6.8 \pm 1.5^{\mathrm{b}}$ & $247.5 \pm 43.4^{\mathrm{b}}$ \\
\hline
\end{tabular}

${ }^{\mathrm{a}} \mathrm{P}<0.05$ compared to the control group; ${ }^{\mathrm{b}} \mathrm{P}<0.01$ compared to the control group. Data are mean \pm standard error of the mean. BLA, blood lactate; DSW, deep sea water; $\mathrm{H}$, high-dose group $\left(2.3 \mathrm{mg} / \mathrm{ml} \mathrm{Mg}^{2+}\right) ; \mathrm{M}$, middle-dose group $\left(0.92 \mathrm{mg} / \mathrm{ml} \mathrm{Mg}^{2+}\right) ; \mathrm{L}$, low-dose group $\left(0.46 \mathrm{mg} / \mathrm{ml} \mathrm{Mg}^{2+}\right)$.

Table V. Effects of DSW on BUN, LDH and CK levels in imprinting control region mice.

\begin{tabular}{lccc}
\hline Group & BUN, mmol/l & LDH, U/l & CK, mmol/1 \\
\hline Control & $11.4 \pm 1.7$ & $1,611.8 \pm 46.3$ & $4,068.5 \pm 11.9$ \\
DSW-H & $9.5 \pm 1.2^{\mathrm{a}}$ & $1,374.9 \pm 67.4^{\mathrm{b}}$ & $1,667.6 \pm 92.6^{\mathrm{b}}$ \\
DSW-M & $10.9 \pm 1.2$ & $1,210.2 \pm 52.8^{\mathrm{b}}$ & $2,991.9 \pm 75.8^{\mathrm{b}}$ \\
DSW-L & $10.8 \pm 0.8$ & $1,280.7 \pm 39.9^{\mathrm{b}}$ & $2,854.0 \pm 94.7^{\mathrm{b}}$ \\
\hline
\end{tabular}

${ }^{\mathrm{a}} \mathrm{P}<0.05$ compared to the control group; ${ }^{\mathrm{b}} \mathrm{P}<0.01$ compared to the control group. Data are mean \pm standard error of the mean. DSW, deep sea water; BUN, blood urea nitrogen; $\mathrm{LDH}$, lactate dehydrogenase; CK, creatine kinase; $\mathrm{H}$, high-dose group $\left(2.3 \mathrm{mg} / \mathrm{ml} \mathrm{Mg}^{2+}\right)$; M, middle-dose group $\left(0.92 \mathrm{mg} / \mathrm{ml} \mathrm{Mg}^{2+}\right)$; L, low-dose group $\left(0.46 \mathrm{mg} / \mathrm{ml} \mathrm{Mg}^{2+}\right)$.

protocols in the commercially available kits from Nanjing Jiancheng Bioengineering Institute.

Statistical analysis. The results are shown as mean \pm standard deviation values. SPSS 21.0 statistical software (IBM, Corp., Armonk, NY, USA) was used for statistical analysis of data. The difference between the control group and each DSW-treated group was accessed using one-way analysis of variance, followed by post hoc Dunnett's comparison test. $\mathrm{P}<0.05$ was considered to indicate a statistically significant difference.

\section{Results}

Effect of DSW on body weight. No significant difference in the initial or final body weight was identified between the control and DSW-treated groups (Table II).

Effect of DSW on weight-loaded forced swimming test (group I). The DSW-high dose group mice were able to swim for longer compared to the control group $(\mathrm{P}<0.05)$ (Table III). The mean duration of the swimming time in the control group was 2,517.8 sec, while the time in the DSW-H group was $3,240.3 \mathrm{sec}$. However, no significant difference was identified between the control group and the DSW-M or DSW-L groups.
Effect of DSW on BLA (group II). Swimming increased BLA and a period of rest reversed this exercise-induced increase (Table IV). The accumulation levels of BLA (including pre-swimming, post-swimming and post-rest) were significantly decreased in the DSW-treated groups compared to those in the control groups (Table IV).

Effect of DSW on BUN, LDH, CK (group III). In general, endurance exercise increases BUN, LDH and CK levels. Table V demonstrates the effect of DSW on BUN, LDH and CK levels in ICR mice after consumption with different concentrations of DSW for 4 weeks. The BUN levels $(9.5 \pm 1.2 \mathrm{mmol} / \mathrm{l})$ of the DSW-H group were significantly different to the control group. Furthermore, the LDH and CK levels of the DSW-treated groups were significantly lower compared to the control group.

Effect of DSW on glycogen (group IV). No significant difference was observed for the storage content of glycogen in the liver and right gastrocnemius between each group (Fig. 2). MDA, as one of the thiobarbituric acid-reactive substances, is an indicator of lipid peroxidation. As the result, the DSW-treated groups exhibited significantly lower plasma MDA concentrations compared to that in the control group. By contrast, the DSW-H group showed significantly higher SOD and GSH-Px activities compared to the control group (Fig. 3).

\section{Discussion}

The results showed that DSW improved exercise capacity and accelerated the recovery from physical fatigue, which was associated with a decreased BLA curve, MDA levels, post-swimming concentrations of BUN, LDH and CK levels, and an increase of antioxidant enzyme activity such as SOD and GSH-Px.

Physical exhaustion is a special type of fatigue. The mice swam until the muscles could not sustain movement, which was associated with their physical condition. Physical condition was therefore one of the evaluation indexes of delaying fatigue during swimming. The present study clearly showed that DSW at a high concentration extended the exhaustive swimming time in the weight-loaded swimming test, which proved that this concentration of DSW could enhance exercise capacity.

The accumulation of BLA in muscle and blood is one of the dominant causes of physical fatigue (22). As the product 


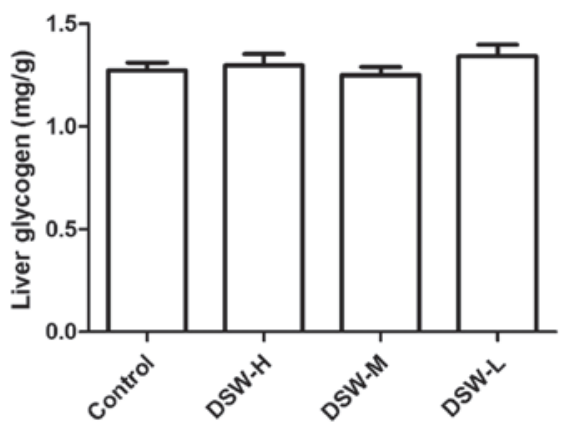

B

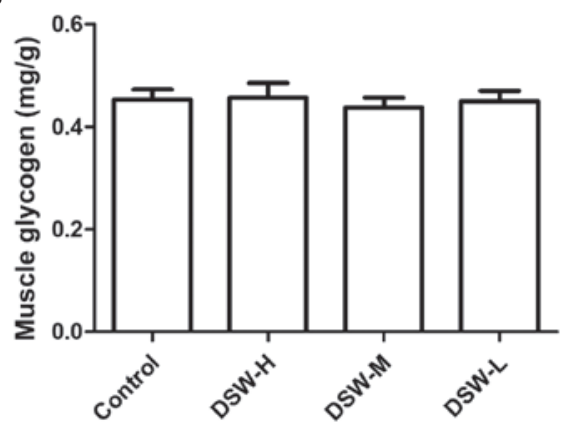

Figure 2. Effect of DSW on (A) liver glycogen and (B) muscle glycogen in imprinting control region mice. Data are mean \pm standard error of the mean. DSW, deep sea water; $\mathrm{H}$, high-dose group $\left(2.3 \mathrm{mg} / \mathrm{ml} \mathrm{Mg}^{2+}\right)$; M, middle-dose group $\left(0.92 \mathrm{mg} / \mathrm{ml} \mathrm{Mg}^{2+}\right)$; $\mathrm{L}$, low-dose group $\left(0.46 \mathrm{mg} / \mathrm{ml} \mathrm{Mg}^{2+}\right)$.

A

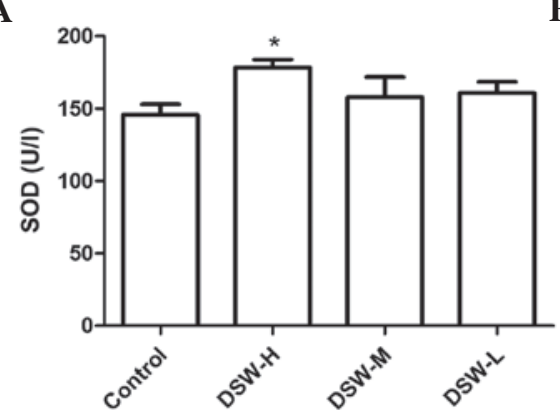

B

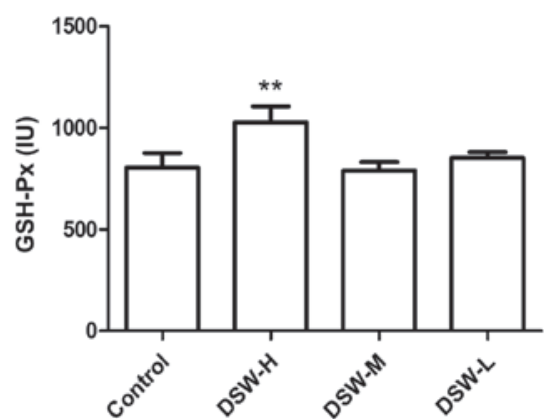

C

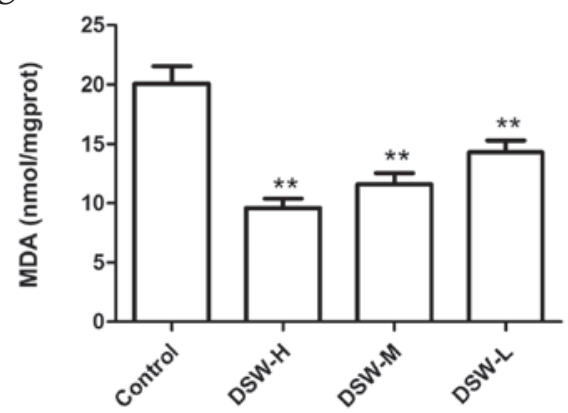

Figure 3. Effect of DSW on (A) SOD, (B) GSH-PX and (C) MDA in imprinting control region mice. Data are mean \pm standard error of the mean. ${ }^{* *} \mathrm{P}<0.01$ compared to the control group. DSW, deep sea water; $\mathrm{H}$, high-dose group ( $\left.2.3 \mathrm{mg} / \mathrm{ml} \mathrm{Mg}^{2+}\right)$; $\mathrm{M}$, middle-dose group (0.92 mg/ml $\left.\mathrm{Mg}{ }^{2+}\right)$; L, low-dose group $\left(0.46 \mathrm{mg} / \mathrm{ml} \mathrm{Mg}^{2+}\right)$; SOD, superoxide dismutase; GSH-PX, glutathione peroxidase; MDA, malondialdehyde.

of glycolysis under anaerobic conditions, the increase in BLA would reduce the internal $\mathrm{pH}$, which may cause an aching muscle pain. Boron, a trace element in DSW, has been found to reduce an exercise-induced rise in plasma lactate (23). Certain changes in enzyme activity, such as LDH and CK, can be used as an indication of damage of the membrane permeability in skeletal muscle and the recovery of sensitive biochemical indicators (24). It is known that the higher the BUN level increases following exercise, the worse the capability to adapt to exercise-loading is. As the product of energy metabolism, BUN is an important indicator of fatigue status, which reflects the ability to adapt to exercise (25). It has been proved that rats subjected to a rubidium-free diet showed higher BUN levels compared to the rats fed with rubidium (26). Rubidium is also an important element of DSW. Glycogen is one of the storage forms of energy in the living body. During strenuous exercise, the capability of glycogen storage prior to exercise can directly affect the ability to exercise (27). However, in the current study, no significant difference was observed between the control and DSW-treated groups.

Investigations of the connection between ROS and diseases have recently attracted increasing attention. ROS can be controlled by numerous types of antioxidant enzymes, such as SOD and GSH-Px (28). Alternatively, MDA as a cause of lipid peroxidation may lead to membranous dysfunction of the cells and mitochondria(29). According to Harman's theory of radicals, strenuous exercise can disrupt the balance of the oxidative and antioxidant system, resulting in the accumulation of reactive radicals, which limits the continuation of exercise (30). The increased level of metabolism, energy consumption, oxygen consumption and body oxygen demand exceeds the actual oxygen uptake during exercising. Simultaneously, the body is in a relatively hypoxic state, leading to an increase in radicals. The accumulation of oxidative metabolite, along with the relative decline of antioxidant enzyme activity may cause lipid peroxidation, leading to oxidative damage.

Previous studies have identified the anti-fatigue effect of DSW in rats and humans $(18,20)$. In the present study, ICR mice were used as an alternative model to determine the anti-fatigue effect of DSW and its mechanism. As reported in certain previous studies, the increased generation of radicals during exercise and the decreased exercise capacity are most closely associated with the performance of radicals and lipid peroxidation in the biofilm of various organs. GSH, SOD and catalase (CAT) levels of the mice fed with antioxidants, such as carvedilol and melatonin, were increased while the lipid peroxidation was attenuated (31).

From the aforementioned results, DSW demonstrated the properties of fatigue resistance and oxidizability. In the view of the association between fatigue and oxidative damage, we speculate that DSW may perform the anti-fatigue effect by increasing the antioxidant activity, possibly as follows. $\mathrm{Mg}$, which participates in energy metabolism, catalyzing or activating $>300$ types of enzymes, is a necessary cofactor of a series of adenosine triphosphate (ATP) enzymes, and has an extremely important role in the promotion of protein 
synthesis. In addition, $\mathrm{Mg}$ is involved in signal transduction, affecting parathyroid secretion. The study by Rock et al (32) study mentioned that free radical-mediated injury could contribute to skeletal muscle lesions resulting from $\mathrm{Mg}$ deficiency. Mg deficiency has been closely associated with production of ROS, cytokines and eicosanoids, along with vascular compromise in vivo (33). The activity center of GSH-Px is selenocysteine, and selenium is a necessary part of GSH-Px (34). There is a direct association between inoxidizability and trace elements. Determination of GSH-Px can be used as a measure of the vitality of the selenium levels of a biochemical indicator. Coenzyme $\mathrm{Q}$ has an anti-fatigue effect in mice (35). The compound of coenzym $Q$ requires selenium, and its enzyme activity is associated with the content of selenium. Coenzyme $\mathrm{Q}$ is the important electronic delivery vector of mitochondrial respiratory chain redox and contributes to mitochondrial ATP synthesis, as well as non-enzymatic antioxidants (35). Lithium can increase the capability for scavenging free radical in animals, and increases the resilience of a cell against destructive free radical attack $(18,36)$. In addition, trace elements such as copper and zinc are highly correlated to antioxidants (37). CuZn-SOD is an SOD that can scavenge superoxide anion radicals and protect cells from damage. Copper and zinc constitute the prosthetic group of CuZn-SOD. Zinc is associated with the stability of the enzyme whereas copper is associated with the activity of the enzyme. The long issimus muscle area and percentage of muscling were increased in pigs fed by chromium picolinate (38), which indicates that chromium may strengthen muscles.

By contrast, the main ingredients of DSW, taken from the west rim of the Pacific Ocean in the present study, were $\mathrm{Mg}$, calcium, potassium, cobalt, selenium, zinc, boron, chromium and vanadium. Therefore, DSW can supply a variety of minerals and trace elements required for the antioxidant system, which serve to improve the activity of antioxidant enzymes to reduce lipid peroxidation level, resist exercise-induced oxidative stress and ultimately cause an anti-fatigue effect to promote physical recovery within sports.

The objective of the present study was to determine the anti-fatigue and antioxidant effect of DSW. According to the results of the present study, DSW may perform the anti-fatigue effect by increasing antioxidant activity. However, even though DSW is rich in a wide variety of trace elements, the type and content of elements are different in different ocean areas and at different depths of the same ocean. In addition, as DSW is a natural compound that contains numerous types of minerals and trace element, it is a challenge to determine the effect of every aspect in each element. Despite the results suggesting the association between fatigue resistance and inoxidizability, further study to demonstrate the antioxidant effect of DSW is required. It has been reported that antioxidants could improve the capability of exercise (7). In addition, the present results showed the inoxidizability of DSW in the pre-exercise stage, so therefore the inoxidizability contributed to fatigue resistance. Future research should investigate the inoxidizability from further aspects, such as lipid hydroperoxide and CAT. Furthermore, a comparison of the inoxidizability of pre-exercise and post-exercise is necessary.
In conclusion, DSW has the ability to alleviate physical fatigue of ICR mice by decreasing BLA, BUN, LDH, CK and MDA, and enhancing antioxidant capacity such as SOD and GSH-Px. Although the present paper provides certain inoxidizability evidence of DSW to explain the anti-fatigue mechanisms, it requires more advanced research to identify the further mechanisms.

\section{Acknowledgements}

The authors would like to thank Pacific Deep Ocean Biotech Co., Ltd., for providing DSW. The present study was supported by the National Natural Science Foundation of China (grant nos. 81302892, 81373520 and 81400231), Guangdong Natural Science Foundation (grant nos. S2013040016226 and S2013010014777) and the Science and Technology Planning Project of Guangdong Province (grant no. 2014A020221013).

\section{References}

1. Mehta RK and Agnew MJ: Influence of mental workload on muscle endurance, fatigue, and recovery during intermittent static work. Eur J Appl Physiol 112: 2891-2902, 2012.

2. Lee JC, Kao JY, Kuo DH, Liao CF, Huang CH, Fan LL and Way TD: Antifatigue and antioxidant activity of alcoholic extract from Saussurea involucrata. J Tradit Complement Med 1: 64-68, 2011.

3. Kennedy G, Spence VA, McLaren M, Hill A, Underwood C and Belch JJ: Oxidative stress levels are raised in chronic fatigue syndrome and are associated with clinical symptoms. Free Radic Biol Med 39: 584-589, 2005.

4. Coombes JS, Rowell B, Dodd SL, Demirel HA, Naito H, Shanely RA and Powers SK: Effects of vitamin E deficiency on fatigue and muscle contractile properties. Eur J Appl Physiol 87: 272-277, 2002.

5. Davies KJ, Quintanilha AT, Brooks GA and Packer L: Free radicals and tissue damage produced by exercise. Biochem Biophys Res Commun 107: 1198-1205, 1982.

6. Valko M, Leibfritz D, Moncol J, Cronin MT, Mazur M and Telser J: Free radicals and antioxidants in normal physiological functions and human disease. Int J Biochem Cell Biol 39: 44-84, 2007.

7. Powers SK, DeRuisseau KC, Quindry J and Hamilton KL: Dietary antioxidants and exercise. J Sports Sci 22: 81-94, 2004.

8. Bak JP, Kim YM, Son J, Kim CJ and Kim EH: Application of concentrated deep sea water inhibits the development of atopic dermatitis-like skin lesions in NC/Nga mice. BMC Complement Altern Med 12: 108, 2012.

9. Yang CC, Yao CA, Lin YR, Yang JC and Chien CT: Deep-sea water containing selenium provides intestinal protection against duodenal ulcers through the upregulation of $\mathrm{Bcl}-2$ and thioredoxin reductase 1. PLoS One 9: e96006, 2014.

10. Tsuchiya Y, Watanabe A, Fujisawa N, Kaneko T, Ishizu T, Fujimoto T, Nakamura K and Yamamoto M: Effects of desalted deep seawater on hematologic and blood chemical values in mice. Tohoku J Exp Med 203: 175-182, 2004.

11. Sheu MJ, Chou PY, Lin WH, Pan CH, Chien YC, Chung YL, Liu FC and Wu CH: Deep sea water modulates blood pressure and exhibits hypolipidemic effects via the AMPK-ACC pathway: An in vivo study. Mar Drugs 11: 2183-2202, 2013.

12. Katsuda S, Yasukawa T, Nakagawa K, Miyake M, Yamasaki M, Katahira K, Mohri M, Shimizu T and Hazama A: Deep-sea water improves cardiovascular hemodynamics in Kurosawa and Kusanagi-Hypercholesterolemic (KHC) rabbits. Biol Pharm Bull 31: 38-44, 2008.

13. Li PC, Pan CH, Sheu MJ, Wu CC, Ma WF and Wu CH: Deep sea water prevents balloon angioplasty-induced hyperplasia through MMP-2: An in vitro and in vivo study. PLoS One 9: e96927, 2014.

14. He S, Hao J, Peng W, Qiu P, Li C and Guan H: Modulation of lipid metabolism by deep-sea water in cultured human liver (HepG2) cells. Mar Biotechnol (NY) 16: 219-229, 2014.

15. Ha BG, Park JE, Shin EJ and Shon YH: Effects of balanced deep-sea water on adipocyte hypertrophy and liver steatosis in high-fat, diet-induced obese mice. Obesity (Silver Spring) 22: $1669-1678,2014$ 
16. Liu HY, Liu MC, Wang MF, Chen WH, Tsai CY, Wu KH, Lin CT, Shieh YH, Zeng R and Deng WP: Potential osteoporosis recovery by deep sea water through bone regeneration in SAMP8 mice. Evid Based Complement Alternat Med 2013: 161976, 2013.

17. Hataguchi Y, Tai H, Nakajima H and Kimata H: Drinking deep-sea water restores mineral imbalance in atopic eczema/dermatitis syndrome. Eur J Clin Nutr 59: 1093-1096, 2005.

18. Hou CW, Tsai YS, Jean WH, Chen CY, Ivy JL, Huang CY and Kuo $\mathrm{CH}$ : Deep ocean mineral water accelerates recovery from physical fatigue. J Int Soc Sports Nutr 10: 7, 2013

19. Kim S, Chun SY,Lee DH,Lee KS and Nam KS: Mineral-enriched deep-sea water inhibits the metastatic potential of human breast cancer cell lines. Int J Oncol 43: 1691-1700, 2013.

20. Wang ST, Hwang DF, Chen RH, Chen YC, Liang CW, Lin CS and Tsai ML: Effect of deep sea water on the exercise-induced fatigue of rats. J Food Drug Anal 17: 133-141, 2009.

21. Wang J, Huang HH, Cheng YF and Yang GM: Structure analysis and laxative effects of oligosaccharides isolated from bananas. J Med Food 15: 930-935, 2012

22. White GE and Wells GD: The effect of on-hill active recovery performed between runs on blood lactate concentration and fatigue in alpine ski racers. J Strength Cond Res 29: 800-806, 2015.

23. Yazici Z, Kaya Y, Baltaci AK, Mogulkoc R and Oztekin E: The effects of boron administration on plasma leptin and lactate levels in ovariectomized rats which had acute swimming exercise. Neuro Endocrinol Lett 29: 173-177, 2008.

24. Louthrenoo W, Weerayutwattana N, Lertprasertsuke N and Sukitawut W: Serum muscle enzymes, muscle pathology and clinical muscle weakness: Correlation in Thai patients with polymyositis/dermatomyositis. J Med Assoc Thai 85: 26-32, 2002.

25. Wu C, Chen R, Wang XS, Shen B, Yue W and Wu Q: Antioxidant and anti-fatigue activities of phenolic extract from the seed coat of Euryale ferox Salisb. and identification of three phenolic compounds by LC-ESI-MS/MS. Molecules 18: 11003-11021, 2013.

26. Yokoi K, Kimura M and Itokawa Y: Effect of low dietary rubidium on plasma biochemical parameters and mineral levels in rats. Biol Trace Elem Res 51: 199-208, 1996.

27. Lin Y, Liu HL, Fang J, Yu CH, Xiong YK and Yuan K: Anti-fatigue and vasoprotective effects of quercetin-3-O-gentiobiose on oxidative stress and vascular endothelial dysfunction induced by endurance swimming in rats. Food Chem Toxicol 68: 290-296, 2014
28. Yagmurca M, Erdogan H, Iraz M, Songur A, Ucar M and Fadillioglu E: Caffeic acid phenethyl ester as a protective agent against doxorubicin nephrotoxicity in rats. Clin Chim Acta 348: 27-34, 2004.

29. Yu F, Lu S, Yu F, Feng S, McGuire PM, Li R and Wang R: Protective effects of polysaccharide from Euphorbia kansui (Euphorbiaceae) on the swimming exercise-induced oxidative stress in mice. Can J Physiol Pharmacol 84: 1071-1079, 2006.

30. Atamaniuk J, Vidotto C, Tschan H, Bachl N, Stuhlmeier KM and Müller MM: Increased concentrations of cell-free plasma DNA after exhaustive exercise. Clin Chem 50: 1668-1670, 2004.

31. Singh A, Garg V, Gupta S and Kulkarni SK: Role of antioxidants in chronic fatigue syndrome in mice. Indian J Exp Biol 40: 1240-1244, 2002.

32. Rock E, Astier C, Lab C, Vignon X, Gueux E, Motta C and Rayssiguier Y: Dietary magnesium deficiency in rats enhances free radical production in skeletal muscle. J Nutr 125: 1205-1210, 1995.

33. Wiles ME, Wagner TL and Weglicki WB: Effect of acute magnesium deficiency (MgD) on aortic endothelial cell (EC) oxidant production. Life Sci 60: 221-236, 1997.

34. Rahmanto AS and Davies MJ: Selenium-containing amino acids as direct and indirect antioxidants. IUBMB Life 64: 863-871, 2012.

35. Fu X, Ji R and Dam J: Antifatigue effect of coenzyme Q10 in mice. J Med Food 13: 211-215, 2010

36. Adipudi V and Reddy VK: Effect of chronic lithium chloride on membrane adenosine triphosphatases in certain postural muscles of rats. Eur J Pharmacol 259: 7-13, 1994.

37. Nazıroğlu M and Yürekli VA: Effects of antiepileptic drugs on antioxidant and oxidant molecular pathways: Focus on trace elements. Cell Mol Neurobiol 33: 589-599, 2013.

38. Page TG, Southern LL, Ward TL and Thompson DL Jr: Effect of chromium picolinate on growth and serum and carcass traits of growing-finishing pigs. J Anim Sci 71: 656-662, 1993. 